\title{
"Dosen Ngajar On the Road": Persepsi Mahasiswa tentang Fenomena Pembelajaran Era Covid-19
}

\author{
Mardianto $^{1 凶}$, Muhammad Shaleh Assingkily $^{2}$ \\ Pendidikan Agama Islam, Universitas Islam Negeri Sumatera Utara, Indonesia( ${ }^{(1)}$ \\ Pendidikan Guru Madrasah Ibtidaiyah, Sekolah Tinggi Ilmu Tarbiyah Al-Ittihadiyah \\ Labuhanbatu Utara, Indonesia(1) \\ DOI: $10.31004 /$ obsesi.v6i1.1374
}

\begin{abstract}
Abstrak
Ngajar on the road merupakan fenomena "baru" sejak pandemi Covid-19, di mana dosen mengajar mahasiswa melalui aplikasi Zoom sambil mengendarai atau menumpangi mobil. Tulisan ini bertujuan untuk menganalisa persepsi mahasiswa prodi PIAUD STIT Al-Ittihadiyah Labuhanbatu Utara tentang fenomena dosen ngajar on the road di era pandemi Covid-19. Penelitian ini menggunakan pendekatan kualitatif dengan metode field research untuk mengungkap dan mengumpulkan data penelitian melalui teknik observasi, wawancara dan studi dokumen yang disesuaikan dengan protokol kesehatan. Melalui penelitian ini, ditemukan 2 (dua) hasil, yaitu (1) mahasiswa menganggap bahwa ngajar on the road memiliki dampak negatif (meliputi; bahaya dan melanggar lalu lintas, tidak efektif, suara bising klakson di jalanan, teladan tidak baik bagi mahasiswa, hingga konsentrasi belajar yang tidak fokus) dan dampak positif (meliputi; pembelajaran lebih fleksibel dan tepat waktu). (2) pola pembelajaran yang diterapkan oleh dosen selama pandemi Covid-19 meliputi presentasi via Youtube, diskusi dan tanya jawab via Zoom atau WhatsApp Group.
\end{abstract}

Kata Kunci: era covid-19; ngajar on the road; pembelajaran; persepsi mahasiswa piaud.

\begin{abstract}
Ngajar on the road is a "new" phenomenon since the Covid-19 pandemic, where lecturers teach students through the Zoom application while driving or riding a car. The behavior of teaching lecturers on the road received positive and negative responses from students, including students of the PIAUD STIT Al-Ittihadiyah study program, North Labuhanbatu. This paper aims to analyze the perceptions of students of the PIAUD STIT Al-Ittihadiyah North Labuhanbatu study program about the phenomenon of lecturers teaching on the road in the era of the Covid-19 pandemic. The focus of the discussion of this research is on the aspects of how students perceive teaching on the road in the Covid-19 era and how the learning patterns are applied by lecturers. This study used a qualitative approach with field research methods to reveal and collect research data through observation, interview and document study techniques adapted to health protocols. Through this research, 2 (two) results were found, namely (1) students considered that teaching on the road had a negative impact (including; dangers and traffic violations, ineffective, horn noise on the streets, bad role models for students, until learning concentration that is not focused) and positive impacts (including; more flexible and timely learning). (2) the learning patterns applied by lecturers during the Covid-19 pandemic include presentations via Youtube, discussions and questions and answers via Zoom or WhatsApp Group.
\end{abstract}

Keywords: covid-19 era; ngajar on the road; learning; perceptions of piaud students.

Copyright (c) 2021 Mardianto, Muhammad Shaleh Assingkily

$\triangle$ Corresponding author:

Email Address: mardianto@uinsu.ac.id (Medan-Sumatera Utara, Indonesia)

Received 22 May 2021, Accepted 5 June 2021, Published 10 June 2021 


\section{PENDAHULUAN}

Pembelajaran online merupakan fenomena yang tidak asing dalam dunia pendidikan sejak pandemi Covid-19 (Gunawan, Suranti \& Fathoroni, 2020; Lubis, et.al., 2020). Berbagai platform pembelajaran pun familiar digunakan oleh kalangan mahasiswa maupun dosen, seperti WhatsApp Group (WAG) (Chika, Saragih \& Astuti, 2020; Pustikayasa, 2019; Hutami \& Nugraheni, 2020; Suryadi, Ginanjar \& Priyatna, 2018), Google Meet-Classroom (Sawitri, 2020; Nalurita, 2021; Mahardini, 2020; Umairoh \& Zulfah, 2020; Longa, 2021), Zoom (Fitrianto, 2021; Kastrena, et.al., 2020; Vhalery, et.al., 2021; Monica \& Fitriawati, 2020; Fitriyani, et.al., 2020), bahkan Youtube (Christian, et.al., 2020; Irmade, 2020; Baihaqi, et.al., 2020). Selain disebabkan oleh maraknya wabah Covid-19 di Indonesia per Maret 2020 (Sit. \& Assingkily, 2020), pembelajaran online juga dipandang sebagai salah satu bentuk kemajuan teknologi dan inovasi di bidang pendidikan (Anshori, 2018).

Pemanfaatan teknologi dalam pembelajaran bukanlah perihal "baru" dalam dunia pendidikan (Husain, 2014; Anshori, 2018; Indrawati, 2020; Muslihudin \& Arumita, 2016). Sebab, sebelum pandemi Covid-19 di Indonesia, beberapa lembaga pendidikan telah menerapkan pemanfaatan teknologi guna mendukung proses pembelajaran, mulai dari pemanfaatan gadget (Putra, 2017), ICT (Suryadi, 2007), Software dan Televisi (Iswanto, 2017). Meskipun begitu, sejak ditetapkannya status pandemi Covid-19 di Indonesia, pembelajaran yang biasa dilaksanakan secara luring atau tatap muka, 100\% beralih menjadi pembelajaran daring (Pakpahan \& Fitriani, 2020; Astini, 2020a; Astini, 2020b; Assingkily \& Sahlan, 2021; Budiani, 2020) sebagai upaya pemutusan rantai Covid-19 dan penerapan social distancing (Sit. \& Assingkily, 2020).

Fenomena baru juga bermunculan seiring dengan penerapan pembelajaran secara daring atau online, salah satunya yakni ngajar on the road. Ngajar on the road merupakan klaster baru pembelajaran yang dipersepsikan oleh mahasiswa terhadap para dosen yang mengajar via Zoom sambil mengendarai atau menumpangi mobil. Hal ini tentu didasarkan pada pemanfaatan kecanggihan teknologi dalam pembelajaran.

Ngajar on the road atau mengajar sambil berkendara merupakan salah satu alternatif yang digunakan oleh dosen untuk mengajar tepat waktu (Sudarmoyo, 2020; Iskandar, 2019). Selain dipandang sebagai bentuk inovasi pembelajaran (Laila, 2021), perilaku dosen yang mengajar on the road juga menuai banyak tanggapan "negatif" dari kalangan mahasiswa, mulai dari aspek bahaya menggunakan handphone sambil berkendara (Mahawati \& Prasetya, 2013; Setiawati \& Lubis, 2019), ketidaknyamanan lingkungan dan situasi belajar (Ashari, Ismet, \& Darman, 2014), dan konsentrasi belajar yang terganggu akibat bisingnya suara kendaraan dalam perjalanan (Halil, Yanis \& Noer, 2015).

Berdasarkan studi pendahuluan terhadap 3 (tiga) mahasiswa prodi PIAUD STIT AlIttihadiyah Labuhanbatu Utara pada tanggal 10 dan 17 Februari 2021, acapkali dosen yang mengajar via Zoom sambil berkendara membuat perhatian dan konsentrasi belajar terganggu. Sebab, fokus dosen terbagi menjadi dua, di satu sisi fokus mengajar, namun sisi lain fokus dalam perjalanan. Di samping itu, terdapat pula pandangan bahwa dosen seolah memaksakan diri harus mengajar via Zoom sambil berkendara.

Sejatinya, kajian mengenai pembelajaran berbasis online di era Covid-19 telah banyak diteliti oleh peneliti terdahulu. Di antaranya membahas pembelajaran online dari aspek inovasi pembelajaran secara online (Marbun, 2020; Wulandari, et.al., 2020; Sari, Nawawi \& Darmawan, 2020), pemanfaatan teknologi dan tantangannya dalam pembelajaran online (Astini, 2020; Firman, 2020), dampaknya terhadap mental peserta didik ( Watnaya, et.al., 2020), efektivitas pembelajaran online (Dewantara \& Nurgiansah, 2021; Zahra \& Wijayanti, 2020; Nurdin \& Anhusadar, 2021), dan berbagai aplikasi yang digunakan dalam pembelajaran online (Wasyik \& Hamid, 2020; Efriani, Dewantara \& Afandi, 2020; Kurniawan, Purnomo, \& Idris, 2020; Putranti, 2013; Zaenab, 2021; Kuntardi, 2021). Perbedaan penelitian ini dengan penelitian sebelumnya yaitu dari aspek permasalahan dan metode mengajar yang diterapkan oleh dosen selama pandemi Covid-19 yaitu kegiatan mengajar sambil berkendara (on the road). 
Mencermati literature review di atas, dipahami bahwa terdapat klaster "baru" berupa metode pembelajaran yang diterapkan oleh dosen selama pandemi Covid-19 yang belum diteliti sebelumnya, yaitu terkait persepsi mahasiswa terhadap dosen yang mengajar on the road (sambil berkendara atau menumpangi/berada di atas) kendaraan selama pandemi Covid-19. Dengan demikian, secara mendalam peneliti akan menganalisa metode pembelajaran tersebut, yang terangkum dalam judul, "Dosen Ngajar On the Road: Persepsi Mahasiswa PIAUD STIT Al-Ittihadiyah Labuhanbatu Utara tentang Fenomena Pembelajaran Era Covid-19". Melalui penelitian ini, diharapkan dapat menjadi acuan bagi dosen dalam menerapkan pembelajaran online yang efektif, komunikatif, dan edukatif bagi mahasiswa. Lebih lanjut, diperoleh informasi tentang pandangan "positif dan negatif" mahasiswa terkait dosen yang "ngajar on the road".

\section{METODOLOGI}

Adapun pendekatan yang digunakan dalam penelitian ini yaitu pendekatan kualitatif dengan metode studi kasus guna mengeksplor hal-hal baru terkait objek penelitian (Yin, 2009: 25). Fokus pembahasan dalam penelitian ini, metode pembelajaran yang diterapkan oleh dosen selama pembelajaran online, yaitu persepsi mahasiswa tentang dosen yang mengajar on the road. Penelitian dimulai sejak Februari-April 2021. Informan utama penelitian ini yaitu 10 (sepuluh) mahasiswa PIAUD STIT Al-Ittihadiyah Labuhanbatu Utara. Adapun identitas umum dari informan ditampilkan pada tabel 1:

Tabel 1. Identitas Umum Informan

\begin{tabular}{lcccc}
\hline No. & $\begin{array}{c}\text { Inisial } \\
\text { Informan }\end{array}$ & Usia & Jenis Kelamin & Keterangan \\
\hline 1. & NS & 19 Tahun & Perempuan & Mahasiswi PIAUD Sem. IV \\
2. & HDT & 19 Tahun & Perempuan & Mahasiswi PIAUD Sem. IV \\
3. & NHP & 19 Tahun & Perempuan & Mahasiswi PIAUD Sem. IV \\
4 & NRL & 21 Tahun & Perempuan & Mahasiswi PIAUD Sem. IV \\
5. & SS & 20 Tahun & Perempuan & Mahasiswi PIAUD Sem. IV \\
6. & MC & 22 Tahun & Perempuan & Mahasiswi PIAUD Sem. IV \\
7. & NFL & 19 Tahun & Perempuan & Mahasiswi PIAUD Sem. IV \\
8. & N & 20 Tahun & Perempuan & Mahasiswi PIAUD Sem. IV \\
9. & KM & 21 Tahun & Perempuan & Mahasiswi PIAUD Sem. IV \\
10. & RRR & 20 Tahun & Perempuan & Mahasiswi PIAUD Sem. IV \\
\hline
\end{tabular}

Pengumpulan data dilakukan dengan teknik wawancara terstruktur secara individual, baik secara langsung maupun tidak langsung (melalui media) terhadap 10 (sepuluh) mahasiswa PIAUD STIT Al-Ittihadiyah Labuhanbatu Utara melalui teknik snowball sampling untuk memperoleh "data jenuh" (Sugiyono, 2010). Upaya ini dilakukan dengan memperhatikan protokol kesehatan, sehingga alternatif via WhatsApp dan platform media sosial lainnya sangat membantu proses pengumpulan data. Selanjutnya data dianalisis dengan teknik (1) reduksi data, yakni memilah data yang diperoleh dari hasil wawancara (chat WA dan wawancara langsung) sesuai kebutuhan data dalam penelitian, sedangkan data atau informasi yang "agak" jauh dari fokus penelitian maka di-filter; (2) display data, tahap ini, data sebelumnya disajikan kembali oleh peneliti dalam bentuk susunan informasi yang naratif untuk memungkinkan penganalisaan data secara komprehensif, dan (3) penarikan kesimpulan. Kerangka (metodologi) penelitian ditampilkan dalam skema 1. 


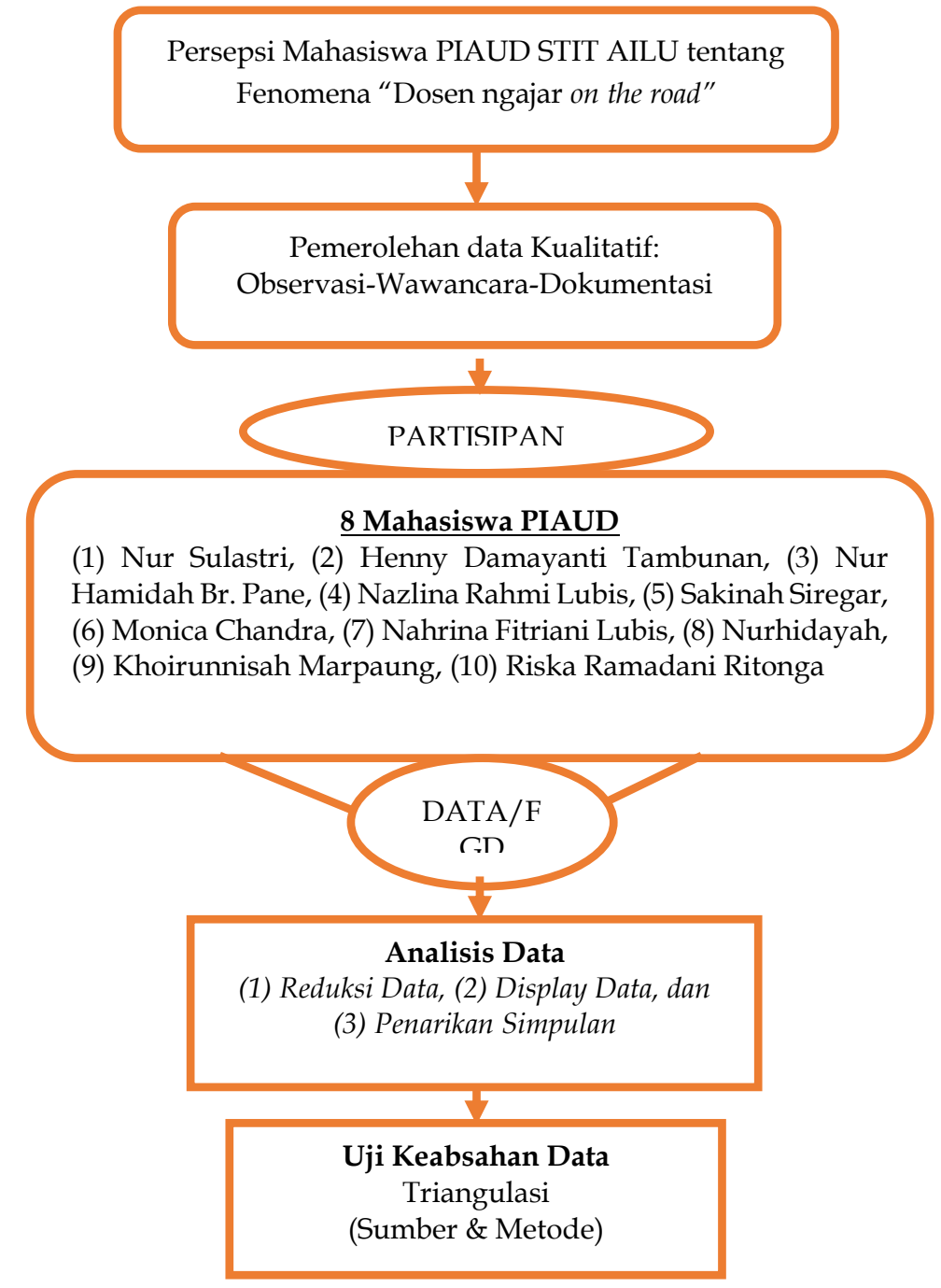

Skema 1. Bagan Metodologi Penelitian

Selanjutnya, penjaminan validitas data penelitian dilakukan dengan teknik triangulasi. Triangulasi dilakukan dengan membandingkan hasil wawancara antara satu partisipan dengan yang lainnya pada tema yang sama (Creswell, 2009), yaitu tema terkait metode pembelajaran "ngajar on the road" yang dilakukan dosen selama pandemi Covid-19. Adapun penggunaan teknik ini dimaksudkan untuk menjaring data dengan berbagai metode dan cara, lebih lanjutnya dengan menyilangkan informasi yang diperoleh agar data yang didapatkan lebih lengkap dan sesuai dengan yang diharapkan.

\section{HASIL DAN PEMBAHASAN}

Pembelajaran online era covid-19 merupakan alternatif tepat digunakan demi keberlanjutan pendidikan. Meskipun begitu, tidak jarang dosen tertangkap kamera Zoom sedang berada di atas kendaraan. Hal ini menuai tanggapan "positif dan negatif" dari kalangan mahasiswa. Sebab, pembelajaran yang idealnya berlangsung secara khidmat dan penuh konsentrasi dalam berinteraksi, malah "dihiasi" dengungan suara kendaraan yang dapat memecah konsentrasi dan fokus dosen dalam memberikan materi pembelajaran.

Menyikapi uraian di atas, berikut dipaparkan persepsi mahasiswa PIAUD STIT AlIttihadiyah Labuhanbatu Utara tentang dosen yang "ngajar on the road" selama pandemi Covid-19. 


\section{Persepsi Mahasiswa Prodi PIAUD STIT Al-Ittihadiyah Labuhanbatu Utara tentang Dosen "Ngajar on the road"}

Kebiasaan baru masyarakat pembelajar (mahasiswa dan dosen) yang berinteraksi melalui aplikasi, menuai berbagai persepsi dari mahasiswa, mulai dari aspek metode (Mayasari, et.al., 2010), profesionalisme (Machfoedz, 1999), keterampilan mengajar (Puspitarini, 2011), kompetensi (Ischayati, 2011), bahkan kinerja seorang dosen (Asri, 2018; Nasution, 2018). Hal ini tentu didasarkan kepada cara dan proses interaksi yang berlangsung antara keduanya (dosen dan mahasiswa). Dengan demikian, seorang dosen tidak dapat mengajar sesuai kehendak semata, melainkan tetap mengikuti prosedur dan standar proses mengajar yang telah ditetapkan oleh instansi (perguruan tinggi) atau peraturan skala nasional (Undang-Undang dan Peraturan lainnya).

Berkaitan dengan pembelajaran online, tidak jarang dosen menampilkan diri mengajar melalui aplikasi Zoom sambil di atas kendaraan (mengemudi atau menumpang). Hal ini tentu memperoleh tanggapan dari mahasiswa, baik tanggapan atau pandangan positif maupun pandangan negatif. Berikut uraiannya:

\section{Pandangan Positif Mahasiswa tentang Dosen "Ngajar on the road"}

Dosen "ngajar on the road" menurut Nur Sulastri, salah satu mahasiswi PIAUD STIT Al-Ittihadiyah Labuhanbatu Utara merupakan fenomena yang tidak bisa terelakkan seiring diterapkannya pembelajaran secara daring. Berikut kutipan wawancaranya:

“...tidak masalah Pak, kalau dosen ngajarnya sambil membawa kendaraan atau menumpangi kendaraan. Saya sebagai mahasiswa menganggap mungkin dosen ada kesibukan tertentu, jadinya harus nge-Zoom di perjalanan. Jadi, belajar tetap tepat waktu, dan dosen pun bisa melanjutkan tugasnya Pak."

Kutipan wawancara di atas, menunjukkan bahwa ngajar on the road bukanlah hal yang asing di era digital saat ini. Menurut Idris (2009), kecanggihan aplikasi teknologi pendidikan di era gitital menjadi kebutuhan primer masyarakat pembelajar (pendidik maupun peserta didik), ketergantungan masyarakat terhadap internet tidak terpisahkan. Untuk itu, "dunia pendidikan" tidak boleh anti terhadap perubahan, termasuk dengan penerapan sistem pembelajaran online.

Meskipun pembelajaran online merupakan "buah" dari inovasi pendidikan, Tambunan dan Pane (mahasiswa PIAUD STIT Al-Ittihadiyah Labuhanbatu Utara) menuturkan bahwa "...pembelajaran daring melalui Zoom, sah-sah saja dilakukan di atas mobil, asal jangan dosennya yang jadi supir (mengemudi), karena akan membahayakan keselamatan. Tapi kalau dosennya ada supir di depan, boleh. Karena kita juga udah maklum dengan kesibukan dosen Pak." Kutipan wawancara ini, senada dengan yang diungkapkan Jaya (2020), bahwa kecanggihan teknologi jangan sampai menggerus nilai-nilai edukasi dalam proses komunikasi dan pembelajaran.

Lebih lanjut, NRL (mahasiswa PIAUD STIT Al-Ittihadiyah Labuhanbatu Utara) menuturkan: "...sebenarnya ga ada masalah sih Pak kalau dosennya mau ngajar dari rumahkah, on the road di mobilkah, atau bus umumkah, karena ini sudah lazim sejak ada Covid-19 ni Pak. Terpenting menurut saya, belajarnya harus tetap nyaman dan kondusif, jangan sampai gara-gara kita Zoom di tempat umum, orang lain terganggu, mahasiswa juga terganggu dengan bisingnya kendaraan, begitupun sebaliknya untuk dosen." Senada dengan ini, Mustika (2015) menjelaskan bahwa penggunaan media yang serba canggih janganlah menjadikan orang sekitar terganggu saat berlangsungnya proses pembelajaran, melainkan menjadi media yang mendukung terciptanya pembelajaran kondusif.

Dengan demikian, dipahami bahwa sebagian mahasiswa PIAUD STIT Al-Ittihadiyah Labuhanbatu Utara memandang pembelajaran online yang diterapkan dosen dengan sistem "ngajar on the road" sah-sah saja untuk dilakukan, dengan catatan tidak melanggar Undang- 
undang lalu lintas (menggunakan gadget sambil mengemudi) dan tidak mengganggu orang sekitar demi terciptanya pembelajaran kondusif.

\section{Pandangan Negatif Mahasiswa tentang Dosen "Ngajar on the road"}

Menurut MC, salah satu mahasiswa PIAUD STIT Al-Ittihadiyah Labuhanbatu Utara, "...dosen yang ngajar on the road adalah perilaku yang melanggar aturan lalu lintas, ditambah lagi itu juga membahayakan diri serta keselamatan dari dosen itu sendiri."

Senada dengan ini, Wicaksono (2019) Menggunakan smartphone sambil mengemudi mobil merupakan salah satu bentuk pelanggaran pidana yang diatur dalam Undang-Undang Nomor 22 Tahun 2009 tentang Lalu Lintas dan Angkutan Jalan.

Mengacu pada uraian di atas, dipahami bahwa pelanggaran yang dimaksud apabila dosen yang mengajar secara online sekaligus mengemudikan mobil. Lain halnya dengan dosen yang "ngajar on the road" berposisi sebagai penumpang, tentu lebih fleksibel mengajar tanpa harus memperhatikan kemudi mobil. Begitupun, ketika diwawancarai, NFL \& N mengaku tidak sepakat dengan perilaku dosen yang mengajar on the road, berikut kutipan wawancaranya:

“...menurut kami Pak, tidak elok dosen ngajar via Zoom sambil berada di mobil, bukan karena dosennya hanya berposisi sebagai penumpang lantas boleh Zoom dari mobil. Yang paling penting itukan bagi kami proses pembelajarannya fokus, penuh konsentrasi dan diupayakan semaksimal mungkin Pak. Nah, gimana ceritanya Pak dosen bisa fokus kalau di perjalanan bising suara kendaraan."

Lebih lanjut, KM menambahkan:

“...seharusnya Pak, dosen yang kepepet mau nge-Zoom sambil dalam perjalanan di atas mobil menunda saja waktu pembelajaran. Beliau kan dosen Pak, jadi bisa kok ubah waktu belajar, ganti hari atau ganti waktu lainnya. Tentu sesuai kesepakatan bersama mahasiswa juga dong Pak, agar fair. Itu lebih aman menurut saya Pak."

Mencermati kutipan di atas, dipahami bahwa efektivitas pembelajaran sulit diperoleh bila dosen "ngajar on the road". Hal ini didasarkan pada ketidakkondusifan pembelajaran online yang diimbangi dengan suara bising dalam perjalanan. Berkaitan dengan ini, Rahayu, et.al., (2016) menyebutkan bahwa kebisingan suara lalu lintas sangat berpengaruh terhadap tingkat kenyamanan belajar. Dalam potongan kutipan wawancara, Ritonga (mahasiswa PIAUD STIT AILU) juga menambahkan, “...daripada dosen harus nge-Zoom sambil di perjalanan yang kerap kali diselingi suara bising kendaraan Pak, bagus beliau tunda sejenak sampai ke rumah, agar nyaman, kondusif dan efektif."

Sejatinya, dosen yang mengajar on the road didasari motif tepat waktu dan disiplin, sehingga tidak ada jadwal mengajar yang terlewatkan. Begitupun, hal ini terkesan seperti memaksakan diri sehingga harus mengajar dalam perjalanan. Senada dengan ini, SS (mahasiswa PIAUD STIT AILU) menuturkan, “...perilaku dosen yang ngajar on the road dari aplikasi Zoom, menurut saya dosennya seperti tergesa-gesa Pak, seolah-olah mahasiswa memaksa dia untuk mengajar tepat waktu, sehingga dia mengajar di mobil. Padahal lebih banyak kelemahannya Pak, suara bising perjalanan, materi tidak jelas terdengar, kalau memang terdesak sekali. Lebih baik berhenti sejenak dulu mobilnya Pak, baru lanjutkan mengajar." Lebih lanjut, $\mathrm{N}$ menambahkan bahwa, "...Kegiatan pembelajaran via Zoom di rumah saja masih ada kendala, jaringan internetlah atau yang lain, konon lagi sambil di perjalanan Pak?".

Berkaitan dengan jaringan internet, Nainggolan, et.al., (2020) dalam penelitiannya telah men-survei dosen FKIP Universitas HKBP Nommensen Medan dan diperoleh informasi bahwa kendala terbesar dosen dalam pelaksanaan perkuliahan online adalah gangguan jaringan internet.

Mencermati uraian di atas, dipahami bahwa terdapat banyak pandangan yang "negatif" dari kalangan mahasiswa terhadap perilaku dosen yang mengajar "on the road". 
Sebab, berdampak negatif pada keselamatan dosen, tidak optimalnya penjelasan materi ajar, kondisi dan situasi pembelajaran yang tidak kondusif, serta kendala jaringan internet yang tidak stabil. Untuk itu, pihak perguruan tinggi perlu menetapkan aturan khusus terkait sistem pembelajaran online selama pandemi Covid-19 di Indonesia.

\section{Pola Pembelajaran Dosen "Ngajar on the road" Presentasi via Youtube}

Presentasi merupakan performa kontekstual yang dilakukan mahasiswa untuk memaparkan hasil diskusinya, terangkum dalam format makalah, artikel atau tugas ilmiah lainnya (Ali \& Mulu, 2020). Kegiatan presentasi lazimnya dilakukan secara tatap muka di depan kelas, begitupun sejak era pandemi Covid-19, banyak dosen yang mengubah presentasi di depan kelas dengan presentasi via Youtube. Selain karena aplikasi ini digandrungi oleh seluruh lapisan masyarakat, dosen juga tetap dapat menilai performa yang ditampilkan oleh mahasiswa.

Berkaitan dengan ini, RRR (mahasiswi PIAUD STIT Al-Ittihadiyah Labuhanbatu Utara) menuturkan bahwa, "...kami selama ini presentasinya via Youtube Pak. Awalnya bingung juga sih Pak, presentasi di Youtube maksudnya gimana, ternyata ini adalah pengganti presentasi yang biasanya di kelas Pak." Lebih lanjut, KM (mahasiswi PIAUD STIT Al-Ittihadiyah Labuhanbatu Utara) menambahkan, “...presentasi dari Youtube ini ada seru-serunya sih Pak, kita berani tampil di depan kamera, eh ternyata bukan hanya disaksikan diri sendiri, tapi bisa banyak orang. Makanya kalau tak menarik rada-rada malu juga uploadnya Pak. Tapi yang namanya tugas mau gimana lagi Pak." Inilah yang diklasifikasikan oleh Ayuningtias, et.al. (2021) sebagai kelebihan dan kelemahan penggunaan youtube sebagai alternatif presentasi.

Berkaitan dengan proses presentasi via Youtube, SS (mahasiswi PIAUD STIT AlIttihadiyah Labuhanbatu Utara) menuturkan bahwa:

“...Adapun proses presentasi via Youtube, di mana mahasiswa ditugaskan oleh dosen membentuk kelompok dan tema. Setelah itu, mahasiswa meng-upload video yang dikerjakan secara berkelompok di akun channel youtube pribadi atau kelasnya. Kemudian, mahasiswa yang memperoleh giliran tampil presentasi, dapat mengirimkan link URL videonya ke grup WA kelas."

Kutipan wawancara di atas menunjukkan peranan Youtube sebagai alternatif media presentasi mahasiswa. Presentasi via Youtube merupakan alternatif menilai kemampuan mahasiswa dalam melaporkan hasil tugas ilmiahnya (Risnani \& Husin, 2019). Lebih dari itu, dari aspek teori edupreneurship, ini juga bagian dari mahasiswa dan dosen untuk bekerjasama mengimplementasikan pendidikan yang memiliki "nilai entrepreneurship" di era digital melalui konten positif di Youtube (Assingkily \& Rohman, 2019; Pelipa \& Marganingsih, 2019).

Di samping berbagai kelebihannya, NHP (Salah satu mahasiswi PIAUD STIT AlIttihadiyah Labuhanbatu Utara) menuturkan bahwa presentasi via Youtube juga memiliki kelemahan, berikut kutipan wawancaranya:

"...salah satu kelemahan youtube menurut saya Pak, konten yang ditampilkan rentan copypaste karya orang lain. Karena kan dosennya nyuruh buat tugas presentasi, diupload ke Channel youtube kami pribadi atau Channel youtube kelas Pak. Jadi, ya namanya juga online, biasanya mau copy-copy paste Pak."

Mengomentari kutipan di atas, dipahami bahwa kecanggihan internet sebagai alternatif presentasi perkuliahan, juga memiliki kelemahan dalam implementasinya. Untuk itu, diperlukan standarisasi dari internal lembaga atau lebih baik skala kebijakan pendidikan nasional tentang tugas mahasiswa di era Covid-19 yang ditampilkan dan dapat diakses publik melalui Youtube.

Berdasarkan uraian di atas, dipahami bahwa presentasi kuliah via Youtube memberi bantuan para pembelajar (dosen maupun mahasiswa). Hal ini didasarkan pada kebijakan 
belajar secara daring (pembelajaran jarak jauh) selama pandemi Covid-19. Begitupun, untuk meminimalisir kecurangan berupa copy-paste karya orang lain, dibutuhkan standarisasi presentasi mahasiswa via Youtube oleh pimpinan internal lembaga atau menteri terkait dalam skala nasional. Dengan demikian, interaksi pembelajaran tetap dapat dilaksanakan dengan baik dan sesuai dengan standar yang telah ditetapkan bersama.

\section{Diskusi via Zoom dan WhatsApp Group (WAG)}

Diskusi melalui aplikasi Zoom dan WhatsApp Group (WAG) merupakan hal lazim yang dilakukan oleh dosen dan mahasiswa selama perkuliahan online. Penggunaan aplikasi ini yaitu setelah mahasiswa dan dosen bersama-sama menyaksikan video presentasi yang ditampilkan di youtube, 6-10 menit kemudian mahasiswa dan dosen diskusi via Zoom atau WAG.

Menurut penuturan NS (mahasiswa PIAUD STIT AILU), “...setelah kami diminta dosen menyaksikan video mahasiswa di Youtube Pak, kami pun selanjutnya diskusi via Zoom, nah di sinilah kami kadang-kadang melihat ada dosen yang ngajar sambil di atas mobil Pak. Biasanya kami diskusinya selama 45 menit di Zoom Pak. Lalu jika masih ada waktu luang kami teruskan bahas diskusi dan materi pertemuan selanjutnya via WAG."

Pemanfaatan berbagai aplikasi selama pembelajaran online, memberi kemudahan bagi mahasiswa dan dosen untuk berinteraksi dari lokasi yang berbeda dalam waktu yang sama (Prajana, 2017; Darmaningrat, et.al., 2018). Lebih lanjut, Tangkelani, et.al. (2021) menerangkan bahwa perlu dibuat standar pembelajaran online secara nasional, atau minimal internal instansi/lembaga pendidikan, guna tercipta pembelajaran yang efektif dan bermutu.

Berdasarkan uraian di atas, dipahami bahwa metode pembelajaran di era Covid-19, memanfaatkan berbagai platform aplikasi media sosial untuk proses pembelajaran, seperti Zoom dan WhatsApp Group. Begitupun, kemudahan penggunaan aplikasi ini, menyebabkan muncul metode pembelajaran baru, di mana dosen mengajar sambil berkendara (ngajar on the road). Padahal, pembelajaran sambil berkendara, dapat terganggu jaringan yang unstabil. Untuk itu, dibutuhkan upaya penetapan standar pembelajaran online antara dosen dan mahasiswa, baik standar yang ditetapkan secara nasional, maupun standar internal kampus.

\section{SIMPULAN}

Adapun simpulan penelitian ini, yaitu (1) mahasiswa menganggap bahwa ngajar on the road memiliki dampak negatif (meliputi; bahaya dan melanggar lalu lintas, tidak efektif, suara bising klakson di jalanan, teladan tidak baik bagi mahasiswa, hingga konsentrasi belajar yang tidak fokus) dan dampak positif (meliputi; pembelajaran lebih fleksibel dan tepat waktu). (2) pola pembelajaran yang diterapkan oleh dosen selama pandemi Covid-19 meliputi presentasi via Youtube, diskusi dan tanya jawab via Zoom atau WhatsApp Group. Penelitian ini merekomendasikan agar dibuat standar pembelajaran online secara nasional oleh kementerian terkait, atau minimal standar yang dibuat oleh internal instansi/lembaga perguruan tinggi.

\section{UCAPAN TERIMA KASIH}

Peneliti mengucapkan terimakasih banyak kepada para partisipan (10 mahasiswi PIAUD STIT Al-Ittihadiyah Labuhanbatu Utara) yang telah bersedia memberi informasi terkait dosen "ngajar on the road". Adapun inisial nama para partisipan tersebut yakni, NS, HDT, NHP, NRL, SS, MC, NFL, N, KM, dan RRR. Semoga Allah swt. membalas kebaikan mahasiswa sekalian sebagai suatu amal jariyah yang terus mengalir pahalanya. Aamiin.

\section{DAFTAR PUSTAKA}

Ali, Ferdinandus Ardian \& Hildegardis Mulu. (2020). "Pengembangan Metode Diskusi Bermuatan Presentasi Sistem Rotasi pada Mata Kuliah Program Linier Berbasis Kearifan Lokal" Jurnal Pembelajaran Matematika Inovatif, 3(6). https://www.journal.ikipsiliwangi.ac.id/index.php/jpmi/article/view/6242. 
Anshori, Sodiq. (2018). "Pemanfaatan Teknologi Informasi dan Komunikasi sebagai Media Pembelajaran" Civic-Culture: Jurnal Ilmu Pendidikan PKn dan Sosial Budaya, 88-100. http://194.59.165.171/index.php/CC/article/download/70/114.

Ashari, A., Faisal Ismet \& Darman, D. (2014). “Hubungan Suasana Lingkungan Belajar dalam Kelas dengan Hasil Belajar Siswa pada Mata Diklat Sistem Motor Kelas XI Teknik Kendaraan Ringan SMK Adzkia Padang" Automotive Engineering Education Journals, 1(1). http:// ejournal.unp.ac.id/students/index.php/poto/article/view/917.

Asri, Yoana Nurul. (2018). "Hubungan Persepsi Mahasiswa pada Kinerja Dosen Terhadap Tingkat Kelulusan Mahasiswa" Al-Tanzim: Jurnal Manajemen Pendidikan Islam, 2(2). https:// doi.org/10.33650/al-tanzim.v2i2.394.

Assingkily, Muhammad Shaleh \& Nur Rohman. (2019). “Edupreneurship dalam Pendidikan Dasar Islam" JIP: Jurnal Ilmiah PGMI, 5(2): 111-130. http://jurnal.radenfatah.ac.id/index.php/jip/article/view/3721.

Assingkily, Muhammad Shaleh \& Sahlan. (2021). "Blended Learning di UIN Sumatera Utara Medan: Historisitas \& Pengembangannya di Era Covid-19" Mudabbir: Journal Research and Education Studies, 1(1): 1-11. http://jurnal.permapendissumut.org/index.php/mudabbir/article/view/1.

Astini, Ni Komang Suni. (2020). "Pemanfaatan Teknologi Informasi dalam Pembelajaran Tingkat Sekolah Dasar pada Masa Pandemi Covid-19" Lampuhyang, 11(2): 13-25. http://e-journal.stkipamlapura.ac.id/index.php/jurnallampuhyang/article/view/194.

Astini, Ni Komang Suni. (2020). “Tantangan dan Peluang Pemanfaatan Teknologi Informasi dalam Pembelajaran Online Masa Covid-19" Cetta: Jurnal Ilmu Pendidikan, 3(2): 241-255. http://jayapanguspress.penerbit.org/index.php/cetta/article/view/452.

Ayuningtias, Nadia, et.al. (2021). "Pengembangan Bahan Ajar Video Interaktif Berbasis Youtube Tema 4 Subtema 2 pada Pembelajaran Daring di Kelas I Sekolah Dasar" Skripsi. Jambi: Universitas Jambi. https://repository.unja.ac.id/19355/.

Baihaqi, Achmad, et.al. (2020). "Youtube sebagai Media Pembelajaran Pendidikan Agama Islam Efektif di SMK Nurul Yaqin Sampang" Edusiana: Jurnal Manajemen Pendidikan Islam, 7(1). http://journal.stainim.ac.id/index.php/edusiana/article/view/19.

Budiani, Dini. (2021). "Interaksi Dosen-Mahasiswa pada Pembelajaran Daring Bahasa Jepang" Journal of Japanese Language Education and Linguistic, 5(1): 46-62. https:// doi.org/10.18196/jilel.v5i1.10578.

Chika, U., Saragih, E.M., \& Astuti, D. (2020). “Analisis Kesulitan Belajar Siswa via WhatsApp pada Masa Pandemi Covid-19" Jurnal Mathematic Paedagogic, 5(2). http://www.jurnal.una.ac.id/index.php/jmp/article/view/1918/0.

Christian, Yefta, et.al. (2020). "Pembelajaran Bahasa Inggris Secara Daring Melalui Youtube" the $2^{\text {nd }}$ National Conference of Community Service Project 2020. https://journal.uib.ac.id/index.php/nacospro/article/view/1217.

Creswell, John W. (2009). Research Design Qualitative, Quantitative, and Mixed Methods Approaches. California: SAGE Publications, Inc.

Darmaningrat, Eko Wahyu Tyas, et.al. (2018). "Pemanfaatan Aplikasi Digital Learning untuk Pembelajaran Pengayaan di Sekolah Menengah Kota Surabaya" Sesindo. http://is.its.ac.id/pubs/oajis/index.php/home/detail/1828.

Dewantara, Jagad Aditya \& T Heru Nurgiansah. (2021). “Efektivitas Pembelajaran Daring di Masa Pandemi COVID 19 Bagi Mahasiswa Universitas PGRI Yogyakarta" Jurnal Basicedu, 5(1). https://doi.org/10.31004/basicedu.v5i1.669.

Efriani, E., Dewantara, J.A., \& Afandi, A. (2020). “Pemanfaatan Aplikasi Discord Sebagai Media Pembelajaran Online" Jurnal Teknologi Informasi dan Pendidikan, 13(1): 61-65. http://tip.ppj.unp.ac.id/index.php/tip/article/view/283.

Firman, F. (2020). “Dampak Covid-19 Terhadap Pembelajaran di Perguruan Tinggi” BIOMA: Jurnal Biologi dan Pembelajarannya, 2(1): 14-20. 
https://ojs.unsulbar.ac.id/index.php/bioma/article/view/743.

Fitrianto, Yoga Pratama. (2021). “Pengaruh Pembelajaran Online via Zoom Terhadap Motivasi Belajar Taruna Poltekip (Studi Kasus Taruna Poltekip Prodi Manajemen Pemasyarakatan Tingkat 3)" Nusantara: Jurnal Ilmu Pengetahuan Sosial, 8(1). http://jurnal.um-tapsel.ac.id/index.php/nusantara/article/view/1772.

Fitriyani, et.al. (2020). "Penggunaan Aplikasi Zoom Cloud Meeting pada Proses Pembelajaran Online Sebagai Solusi di Masa Pandemi Covid 19" Edification Journal: Pendidikan Agama Islam, 3(1): 23-34. https://jurnal.staibsllg.ac.id/index.php/ej/article/view/221.

Gunawan, G., Suranti, N.M.Y., \& Fathoroni, F. (2020). "Variations of Models and Learning Platforms for Prospective Teachers During the COVID-19 Pandemic Period" Indonesian Journal of Teacher Education, 1(2): 61-70. https://journal.publicationcenter.com/index.php/ijte/article/view/95.

Halil, Amwal, Amel Yanis, \& Mustafa Noer. (2015). "Pengaruh Kebisingan Lalu Lintas Terhadap Konsentrasi Belajar Siswa SMP N 1 Padang" Jurnal Kesehatan Andalas, 4(1). http://jurnal.fk.unand.ac.id/index.php/jka/article/view/188.

Husain, Chaidar. (2014). "Pemanfaatan Teknologi Informasi dan Komunikasi dalam Pembelajaran di SMA Muhammadiyah Tarakan" Jurnal Kebijakan E Pengembangan Pendidikan, 2(2), 2014. https:// doi.org/10.22219/jkpp.v2i2.1917.

Hutami, M.S. \& Nugraheni, A.S. (2020). "Metode Pembelajaran Melalui WhatsApp Group Sebagai Antisipasi Penyebaran Covid-19 pada AUD di TK ABA Kleco Kotagede" PAUDIA, 9(1). http://journal.upgris.ac.id/index.php/paudia/article/view/6107.

Idris, Husni. (2009). "Aplikasi Teknologi Pendidikan di Era Global" 3(2). http://journal.iainmanado.ac.id/index.php/JII/article/view/555.

Indrawati, Budi. (2020). “Tantangan dan Peluang Pendidikan Tinggi dalam Masa dan Pasca Pandemi Covid-19" Jurnal Kajian Ilmiah, 1(1). http://ejurnal.ubharajaya.ac.id/index.php/JKI/article/view/261.

Irmade, Oka. (2020). "Analisis Penggunaan Media Youtube dalam Belajar Mandiri Pendidikan Jasmani Mahasiswa PG-PAUD” Awlady: Jurnal Pendidikan Anak, 6(2). https://www.syekhnurjati.ac.id/jurnal/index.php/awlady/article/view/6228.

Ischayati, Isni. (2011). "Pengaruh Persepsi Mahasiswa Mengenai Kompetensi Dosen dan Fasilitas Belajar Terhadap Motivasi Belajar Akuntansi Keuangan Menengah pada Mahasiswa FKIP-UMS Progdi Pendidikan Akuntansi Angkatan 2008/2009" Skripsi. Universitas Muhammadiyah Surakarta. http://eprints.ums.ac.id/13013/.

Iskandar, Abdul Malik. (2019). "Interaksi dan Komunikasi Dosen dan Mahasiswa dalam Proses Pendidikan" Al-Din: Jurnal Dakwah dan Sosial Keagamaan, 5(1). http://dx.doi.org/10.35673/ajdsk.v5i1.570.

Iswanto, Rahmat. (2017). "Pembelajaran Bahasa Arab dengan Pemanfaatan Teknologi" Arabiyatuna: Jurnal Bahasa Arab, 1(2). http://journal.iaincurup.ac.id/index.php/ARABIYATUNA/article/view/286.

Jaya, Makmur. (2020). "Penggunaan Teknologi dalam Komunikasi” Qaulan: Jurnal Komunikasi dan Penyiaran Islam, 1(1). https://jurnal.stainmadina.ac.id/index.php/qau/article/view/122.

Kastrena, Ervan, et.al. (2020). "Pembelajaran Peer Teaching Berbasis Zoom Video Sebagai Solusi untuk Meningkatkan Hasil Belajar Passing Bawah Bola Voli Saat Situasi Covid 19" Indonesian Journal of Primary Education, 4(1). https://ejournal.upi.edu/index.php/IJPE/article/view/25133.

Kuntardi, Dina Vebiola Saraswati. (2021). “Zoom Fatigue dan Keberfungsian Sosial di Kalangan Mahasiswa" Jurnal Publisitas, http://ejurnal.stisipolcandradimuka.ac.id/index.php/JurnalPublisitas/article/view $\angle 47$.

Kurniawan, B., Purnomo, A., \& Idris. (2020). “Penggunaan Aplikasi Google Classroom Sebagai Upaya Peningkatan Pembelajaran Online Bagi Guru Matapelajaran IPS” International 
$\begin{array}{llll}\text { Journal of Community } & \text { Service }\end{array}$ https:// ejournal.undiksha.ac.id/index.php/IJCSL/article/view/22236.

Laila, Dahratul. (2021). "Inovasi Perangkat Pembelajaran Menggunakan Aplikasi Podcast" Prosiding Seminar Nasional Pembelajaran Bahasa dan Sastra Indonesia, 3(1): 7-12. http://digilib.unimed.ac.id/41213/.

Longa, Albina Evarista. (2021). “Penggunaan Aplikasi Google Classroom dalam Upaya Meningkatkan Hasil Belajar Matematika pada Siswa Kelas X IPS 3 SMA Negeri 1 Maumere" Journal on Teacher Education, 2(2). https://journal.universitaspahlawan.ac.id/index.php/jote/article/view/1440

Lubis, Rahmat Rifai, et.al. (2020). “Pembelajaran Al-Qur'an Era Covid-19: Tinjauan Metode dan Tujuannya pada Masyarakat di Kutacane Aceh Tenggara" Kuttab: Jurnal Ilmu Pendidikan Islam, $4(2)$. http://journalfai.unisla.ac.id/index.php/kuttab/article/view/275.

Machfoedz, Mas'ud. (1999). “Studi Persepsi Mahasiswa Terhadap Profesionalisme Dosen Akuntansi Perguruan Tinggi" EconPapers, https://econpapers.repec.org/article/uiijaaife/v_3a3_3ay_3a1999_3ai_3a1_3ap_3a128.htm.

Mahardini, M.M.A. (2020). “Analisis Situasi Penggunaan Google Classroom pada Pembelajaran Daring Fisika" Jurnal Pendidikan Fisika, 8(2). https://www.ojs.fkip.ummetro.ac.id/index.php/fisika/article/view/3102.

Mahawati, Eni \& Jaka Prasetya. (2013). “Analisis Penggunaan Handphone Saat Berkendara Terhadap Potensial Kecelakaan Lalu Lintas pada Remaja di Semarang" Semantik, 3(1). http://publikasi.dinus.ac.id/index.php/semantik/article/view/777.

Marbun, Purim. (2020). “Desain Pembelajaran Online pada Era dan Pasca Covid-19" Computer Science Research and Its Development Journal, 12(2): 129-142. http://dx.doi.org/10.22303/csrid.12.2.2020.129-142.

Mayasari, Meirina Dian, et.al. (2010). "Hubungan antara Persepsi Mahasiswa Terhadap Metode Pengajaran Dosen dengan Kecenderungan Prokrastinasi Akademik pada Mahasiswa Fakultas Psikologi Universitas Hang Tuah Surabaya" Insan, 12(2).

Monica, Junita \& Fitriawati, D. (2020). “Efektivitas Penggunaan Aplikasi Zoom Sebagai Media Pembelajaran Online pada Mahasiswa Saat Pandemi Covid-19" Jurnal Communio, 9(2): 1630-1640. http:/ / ejurnal.undana.ac.id/JIKOM/article/view/2416.

Muslihudin, Muhamad \& A. Wulan Arumita. (2016). "Pembuatan Model Penilaian Proses Belajar Mengajar Perguruan Tinggi Menggunakan Fuzzy Simple Additive Weighting (SAW) (Studi: STMIK Pringsewu)" Semnasteknomedia Online, 4(1). https:// ojs.amikom.ac.id/index.php/semnasteknomedia/article/view/1296.

Mustika, Zahara. (2015). “Urgenitas Media dalam Mendukung Proses Pembelajaran yang Kondusif" Circuit: Jurnal Ilmiah Pendidikan Teknik Elektro, 1(1). https://jurnal.arraniry.ac.id/index.php/circuit/article/view/311.

Nainggolan, Juliper, et.al. (2020). "Survei Kendala Dosen Fakultas Keguruan dan Ilmu Pendidikan Universitas HKBP Nommensen dalam Pelaksanaan Perkuliahan Online" Jurnal Suluh Pendidikan, $8(2)$. https://jurnal.uhn.ac.id/index.php/jsp/article/view/269.

Nalurita, Sari. (2021). “Pemanfaatan Aplikasi Google Meet pada Mata Kuliah Teknik Proyeksi Bisnis Semester Gasal Tahun Pelajaran 2020/2021 di Universitas Dirgantara Marsekal Suryadarma (Unsurya) (Studi pada Mahasiswa Prodi Manajemen Kelas G)" Jurnal Ilmiah Manajemen Surya Pasca Scientia, https://journal.universitassuryadarma.ac.id/index.php/jimspc/article/view/593.

Nasution, Yusuf Ramadhan. (2018). "Penerapan Aplikasi Online Angket Persepsi Mahasiswa Terhadap Kinerja Dosen UIN Sumatera Utara Medan" JISTech: Journal of Islamic Science and Technology, 3(2). http://jurnal.uinsu.ac.id/index.php/jistech/article/view/3158.

Nurdin, N. \& Anhusadar, L. (2021). “Efektivitas Pembelajaran Online Pendidik PAUD di 
Tengah Pandemi Covid 19" Jurnal Obsesi: Jurnal Pendidikan Anak Usia Dini, 5(1). https://www.obsesi.or.id/index.php/obsesi/article/view/699.

Pakpahan, Roida \& Yuni Fitriani. (2020). “Analisa Pemanfaatan Teknologi Informasi dalam Pembelajaran Jarak Jauh di Tengah Pandemi Virus Corona Covid-19" JISAMAR: Journal of Information System, Applied, Management, Accounting and Research, 4(2): 30-36. http://journal.stmikjayakarta.ac.id/index.php/jisamar/article/view/181.

Pelipa, Emilia Dewiwati \& Anna Marganingsih. (2019). "Pengaruh Edupreneurship dan Praktek Kerja Terhadap Kemampuan Life Skill Mahasiswa" Jurkami: Jurnal Pendidikan Ekonomi,

http://jurnal.stkippersada.ac.id/jurnal/index.php/JPE/article/view/422.

Prajana, Andika. (2017). "Pemanfaatan Aplikasi WhatsApp untuk Media Pembelajaran dalam Lingkungan UIN Ar-Raniry Banda Aceh" Cyberspace: Jurnal Pendidikan Teknologi Informasi, raniry.ac.id/index.php/cyberspace/article/view/1980. https://www.jurnal.ar-

Puspitarini, Santi. (2011). "Pengaruh Persepsi Mahasiswa atas Keterampilan Mengajar Dosen dan Komunikasi antara Dosen dan Mahasiswa Terhadap Prestasi Belajar Mahasiswa Progdi Pendidikan Akuntansi Angkatan 2008/2009 Universitas Muhammadiyah Surakarta" Skripsi. Universitas Muhammadiyah Surakarta. http://eprints.ums.ac.id/13780/.

Pustikayasa, I.M. (2019). "Grup WhatsApp Sebagai Media Pembelajaran” Widya Genitri: Jurnal Ilmiah Pendidikan, Agama dan Kebudayaan Hindu, 10(2). http://jurnal.stahds.ac.id/widyagenitri/article/view/281.

Putra, CA. (2017). "Pemanfaatan Teknologi Gadget Sebagai Media Pembelajaran" Jurnal $\begin{array}{lll}\text { Pendidikan Teknologi, 2(2): } & \text { 1-10. }\end{array}$ http://journal.umpalangkaraya.ac.id/index.php/bitnet/article/view/752.

Putranti, Nurita. (2014). "Cara Membuat Media Pembelajaran Online Menggunakan Edmodo" Jurnal Pendidikan Informatika dan Sains, 2(2). https://journal.ikippgriptk.ac.id/index.php/saintek/article/view/224.

Rahayu, Setiya, et.al. (2016). “Pengaruh Tingkat Kebisingan Lalu Lintas Terhadap Tingkat Kenyamanan Siswa Saat Pembelajaran di Sekolah Kecamatan Bangil Kabupaten Pasuruan (Studi Kasus di SMP Negeri 3 Bangil dan MTs Negeri Bangil)" Jurnal Pembelajaran Fisika, 5(1). http://jurnal.unej.ac.id/index.php/JPF/article/view/3556.

Risnani, Listika Yusi \& Arief Husin. (2019). "Blended Learning: Pengembangan dan Implementasinya pada Mata Kuliah Fisiologi Tumbuhan" BioEduScience, 3(2). https://doi.org/10.29405/j.bes/3274-834007.

Sari, Mustika, Nawawi, \& Darmawan, H. (2020). “Analisis Pembelajaran di Era Pandemic (Covid-19) pada Program Studi Pendidikan Biologi IKIP PGRI Pontianak" Jurnal Pendidikan Teknologi Informasi dan Komputer, 2(1). https://jurnal.mipatek.ikippgriptk.ac.id/index.php/JPTIK/article/view/150.

Sawitri, Dara. (2020). "Penggunaan Google Meet untuk Work From Home di Era Pandemi Coronavirus Disease 2019 (Covid-19)" Prioritas: Jurnal Pengabdian kepada Masyarakat, 2(1): 13-21. http://jurnal.harapan.ac.id/index.php/Prioritas/article/view/161.

Setiawati, Titin \& Sofiah Lubis. (2019). “Perancangan Iklan Layanan Masyarakat Dampak Negatif Penggunaan Handphone Saat Berkendara di Kota Medan" Proporsi: Jurnal Desain, Multimedia, dan Industri Kreatif, 4(2). http://e-journal.potensiutama.ac.id/ojs/index.php/PROPORSI/article/view/640.

Sit., Masganti \& Muhammad Shaleh Assingkily. (2020). "Persepsi Guru tentang Social Distancing pada Pendidikan AUD Era New Normal" Jurnal Obsesi: Jurnal Pendidikan Anak Usia Dini, 1009-1023. https://www.obsesi.or.id/index.php/obsesi/article/view/756.

Sudarmoyo, S. (2020). "Podcast sebagai Alternatif Media Pembelajaran Jarak Jauh" Edudikara: Jurnal Pendidikan $\mathcal{E}$ Pembelajaran, 5(2): 65-73. 
http://ojs.iptpisurakarta.org/index.php/Edudikara/article/view/212.

Sugiyono. (2010). Metode Penelitian Kuantitatif, Kualitatif, dan RED. Bandung: Alfabeta.

Suryadi, Ace. (2007). "Pemanfaatan ICT dalam Pembelajaran" Jurnal Pendidikan Terbuka dan Jarak Jauh, 8(2): 83-98. http://jurnal.ut.ac.id/index.php/jptjj/article/view/537.

Suryadi, E., Ginanjar, M.H., \& Priyatna, M. (2018). "Penggunaan Sosial Media WhatsApp Pengaruhnya Terhadap Disiplin Belajar Peserta Didik pada Mata Pelajaran Pendidikan Agama Islam (Studi Kasus di SMK Analis Kimia YKPI Bogor)" Edukasi Islami: Jurnal Pendidikan Islam, $7(1)$. http://jurnal.staialhidayahbogor.ac.id/index.php/ei/article/view/211.

Tangkelani, Ehrvina Evrianthy, et.al. (2021). "Persepsi Mahasiswa Program Studi Pendidikan Biologi dalam Pembelajaran Online pada Masa Pandemi Covid-19" Celebes Biodiversitas: Jurnal Sains $\mathcal{E}$ Pendidikan Biologi, 4(1). http://ojs.stkippi.ac.id/index.php/CB/article/view/257.

Umairoh, Putri \& Zulfah, Z. (2020). "Peningkatan Motivasi Belajar Menggunakan Google Classroom di Tengah Pandemi Covid-19 pada Peserta Didik Kelas XI IPS 4 SMAN 1 Bangkinang Kota" Journal on 2(3). https://www.jonedu.org/index.php/joe/article/view/319.

Vhalery, Rendika, et.al. (2021). “Pembelajaran Berbasis Online Zoom pada Kesiapan Belajar Mahasiswa di Masa Pandemi Covid-19" Research and Development Journal of Education, 7(1). https://journal.lppmunindra.ac.id/index.php/RDJE/article/view/9329.

Wasyik, Torikhul \& Abdulloh Hamid. (2020). “Implementasi E-Learning dalam Pembelajaran Alquran Era Covid-19 di Sanggar Tahfidz Entrepreneur Krian Sidoarjo" Edudeena: Journal of Islamic Religious Education, 4(1). https://jurnal.iainkediri.ac.id/index.php/edudeena/article/view/2194/0.

Watnaya, Agus Kusnayat, et.al. (2020). "Pengaruh Teknologi Pembelajaran Kuliah Online di Era Covid-19 dan Dampaknya Terhadap Mental Mahasiswa" Eduteach: Jurnal Edukasi dan Teknologi Pembelajaran, 1(2). https:// doi.org/10.37859/eduteach.v1i2.1987.

Wicaksono, Agustinus Herwindu. (2019). “Tindak Pidana Pelanggaran Pidana Lalu Lintas oleh Anak dalam Proses Acara Peradilan Cepat" Badamai Law Journal, 4(2). https://ppjp.ulm.ac.id/journal/index.php/blj/article/view/9237.

Wulandari, Medita Ayu, et.al. (2020). “Analisis Pembelajaran Daring pada Guru Sekolah Dasar di Era Covid-19" Jurnal Ilmiah P2M STKIP Siliwangi, 7(2). http://ejournal.stkipsiliwangi.ac.id/index.php/p2m/article/view/2002.

Yin, Robert K. (2009). Case Study Research: Design and Methods. California: SAGE Inc.

Zaenab, Z. (2021). "Kolaborasi Zoom dengan WAG sebagai Potret Merdeka Belajar pada Masa New Normal di SMK Negeri 4 Gowa" Jurnal Paedagogy, 8(1). https://ejournal.undikma.ac.id/index.php/pedagogy/article/view/3129.

Zahra, Alifarose Syahda \& Sherina Wijayanti. (2020). “Efektivitas Pembelajaran Basis Online di IAIN Tulungagung dengan Adanya Kebijakan Psychal Distancing Era Pandemi Covid 19" Geram: Jurnal Pendidikan, Bahasa dan Sastra, 8(1). https://journal.uir.ac.id/index.php/geram/article/view/5040. 